\title{
A CONSTRUÇÃO LEGAL-INSTITUCIONAL DA RESOLUÇÃO NEGOCIADA DE CONFLITO NO BRASIL
}

\section{Rodrigo Nuñez Viégas}

(iD) https://orcid.org/0000-0003-0789-0424

Fundaçăo Instituto de Pesca do Estado do Rio de Janeiro (Fiperj), Niterói - RJ e Centro Universitário de Volta Redonda (UniFOA), Volta Redonda - RJ, Brasil. E-mail: mrviegas@gmail.com

DOI: $10.1590 / 349916 / 2019$

\section{Introdução}

A partir dos anos de 1980, com a crise do modelo nacional-desenvolvimentista, surge no Brasil uma série de propostas liberalizantes que foram intentadas no interior dos governos que assumiam o comando do país na época. Com base na crítica ao "Estado intervencionista", tais propostas prescreveram profundas reformas como caminho para a retomada do crescimento econômico. A defesa ideológica dessas reformas foi implementada pelo discurso de modernização e racionalização do Estado, por meio da discussão em torno (i) da delimitação de seu tamanho (onde se encontram as ideias de privatização, terceirização etc.); (ii) do maior ou menor grau de sua intervenção no funcionamento do mercado; (iii) da redefinição das formas de sua

Artigo recebido em: 28/12/2017

Aprovado em: 24/07/2018 intervenção no plano social; (iv) da busca pela superação de formas "burocráticas" de administrá-lo; (v) da adequação das instituições políticas para a intermediação dos interesses; e (vi) da reconfiguração da dita função tradicional do Estado de tratamento dos conflitos em sociedade. ${ }^{1}$

No plano do sistema de justiça, a busca por reforma centrou sua atenção no conjunto geral de instituiçóes e mecanismos, pessoas e procedimentos utilizados para processar e mesmo prevenir conflitos. Partiu-se da ideia de que a representação judicial (tanto de indivíduos quanto de interesses difusos) náo se mostrou suficiente em tornar os novos direitos efetivos para os pobres, inquilinos, consumidores e outras categorias que, durante muito tempo, estiveram privados dos benefícios de uma justiça igualitária. Diante disso, essa reforma constituiu-se em esforços no enfrentamento da inflaçấo de demandas judiciais mediante a criação de órgãos de justiça orientados para a atuação extraju- 
dicial, bem como por meio da criação e do incentivo ao uso de métodos e instrumentos alternativos aos judiciais ou "extrajudiciais". Tal reforma faz parte da terceira "onda" de reforma do sistema de justiça que emerge nos países do mundo ocidental, denominada por Cappelletti e Garth (1988) de "enfoque de acesso à justiça”. ${ }^{2}$

A expectativa pelo uso de métodos alternativos aos judiciais ou "extrajudiciais" fica claramente expressa nas palavras da então ministra do Supremo Tribunal Federal Ellen Gracie, ao afirmar que:

Os métodos alternativos de solução de litígio são melhores do que a solução judicial, que é imposta com a força do Estado, e que padece de uma série de percalços, como a longa duraçáo do processo, como ocorre no Brasil e em outros países. ${ }^{3}$

Para além da criação de novos órgãos de justiça voltados para processar e prevenir conflitos na esfera extrajudicial, observa-se também um esforço no sentido de se buscar recaracterizar ou reconfigurar as formas de atuação de órgãos como o Ministério Público, que passa a reorientar seus profissionais (promotores e procuradores) para que atuem como "mediadores" ou "negociadores", de maneira a buscarem a compreensão dos problemas e interesses envolvidos nos conflitos com o intuito de conduzirem as partes litigantes a acordarem entre si, evitando assim o processo judicial. Desse modo, tais profissionais buscam "desburocratizar" suas formas de tratamento de conflito ao utilizarem métodos e instrumentos extrajudiciais, considerados mais céleres e de menor custo administrativo.

Para a consecução das propostas de reforma do sistema de justiça, há uma focalização em iniciativas na esfera legislativa mediante a criação de leis voltadas para disciplinar órgãos, métodos e instrumentos de tratamento dos conflitos na esfera extrajudicial, assim como alterar (via complementação ou revogação) leis já existentes para atender ao mesmo objetivo. ${ }^{4}$ É assim que o Brasil testemunha, a partir da década de 1980, a introdução em sua legislação de leis voltadas para a criação e regulamentação de órgãos como os Juizados Especiais, de métodos extrajudiciais como a conciliação e a arbitragem e de instrumentos extrajudiciais como o Termo de Ajus- tamento de Conduta (TAC), o Termo de Compromisso de Cessação de Prática (TCC) e Termo de Ajustamento de Gestáo (TAG).

No presente artigo pretendemos identificar as iniciativas realizadas na esfera legislativa para a promoção da reforma do sistema de justiça desenvolvida no Brasil a partir dos anos de 1980. Buscamos demonstrar que tais iniciativas envolvem um processo - ao contrário de uma tendência ocorrida mundialmente de um enxugamento das legislaçôes - de expansão da legislação brasileira como forma de regulamentar órgãos, métodos e instrumentos extrajudiciais de tratamento dos conflitos que chamaremos de construção legal-institucional da resoluçâo negociada de conflito. Ademais, procuramos evidenciar tal processo como resultado do esforço de certos "criadores de regras" que, ao criarem e imporem regras, buscam reconfigurar o que se entende por função "pacificadora" do Estado de tratar os conflitos, justificando suas ações por meio de discursos que reforçam a via extrajudicial como a maneira de tornar mais "pacífico", "consensual" " "célere" o tratamento dos conflitos. Antes de caracterizarmos essa reconfiguração, porém, faz-se necessário problematizarmos a noção da criação do Estado como um meio de "pacificação social".

\section{A função "pacificadora" do Estado de tratar os conflitos sociais}

O Brasil possui uma tradição jurídica inserida em uma perspectiva formalista, que seria o legado das variaçóes do que se denomina "positivismo jurídico". Tal tradição jurídica tem como um de seus alicerces a noção de "paz social" ou de "ordem social" e, nesse sentido, é recorrente na literatura do direito o tema da manutenção da paz e da ordem social como função privilegiada do direito.

A noção de "paz social" ou de "ordem social" refere-se diretamente à ideia da constituição de um Estado moderno que passa a deter o monopólio da soberania jurídico-política e da violência física legítima, expropriando progressivamente as formas tradicionais de "solução" de conflito herdadas na alta Idade Média (Adorno, 1996) - como a autotutela (ou autodefesa), que passa a ser definida como crime, 
seja quando praticada pelo particular, ${ }^{5}$ seja pelo próprio Estado. ${ }^{6}$ Por meio desse monopólio, o Estado passa a absorver o poder de impor autoritariamente sobre os particulares sua "solução" para os conflitos de interesses, por meio da atividade mediante a qual juízes estatais examinam as pretensōes e "resolvem" os conflitos: a jurisdição. Segundo Cintra, Grinover e Dinamarco (1998), o que distingue a jurisdiçāoo das demais funçóes do Estado (legislaçáo, administração) é a finalidade "pacificadora" com que o Estado a exerce. Segundo os autores:

A pacificação é o escopo magno da jurisdição e, por consequência, de todo o sistema processual (uma vez que ele pode ser definido como a disciplina jurídica da jurisdição e seu exercício). É um escopo social, uma vez que se relaciona com o resultado do exercício da jurisdiçáo perante a sociedade e sobre a vida gregária de seus membros e felicidade geral de cada um (Cintra, Grinover e Dinamarco, 1998, pp. 24-25, grifos no original).

O Estado, de forma a atender aos objetivos da jurisdição e sua função "pacificadora", institui o sistema processual, concebendo normas (direito processual), criando órgáos jurisdicionais (juízes e tribunais) e exercendo seu poder por meio deles.

A concepçáo segundo a qual o nascimento do Estado contribui para promover a "paz social" tem suas raízes no que chamamos de "teoria da soberania". Para melhor compreendermos essa teoria, cabe aqui percorrermos a trajetória de análise realizada por Foucault, expondo suas críticas a essa teoria e apresentando suas propostas de superaçâo da mesma.

A perspectiva de Foucault (1999) nos é relevante, vez que o autor conduz sua análise da sociedade fora dos parâmetros jurídicos da "teoria da soberania" e propóe observar a criação do Estado não como um instrumento de pacificação social, mas sim como uma maneira de dar continuidade à guerra da sociedade por outros meios. Para tanto, critica o tratamento jurídico do poder feito por essa teoria e questiona os três elementos em que se fundamenta, o que chamou de "tríplice primitivismo": o do sujeito que deve ser sujeitado; o da unidade de poder que deve ser fundamentada; e o da legitimi- dade que deve ser respeitada (sujeito, unidade de poder e lei).

No que concerne à questão do sujeito, Foucault (1999) interpreta a dicotomia proposta pelos filósofos contratualistas entre o "estado de natureza" e a "civilização" ou "estado civil" como uma forma encontrada por esses teóricos para ligar "o sujeito ao sujeito", estabelecendo uma relação política "do sujeito com o sujeito". Trata-se de conceber o sujeito como um indivíduo dotado naturalmente de direitos ou de capacidades (no "estado de natureza") e colocá-lo como um indivíduo sujeitado em uma relaçáo de poder (após a instituição do Estado civil), percorrendo um movimento que conduz um "indivíduo natural" a um "indivíduo sujeitado". Transforma-se assim um sujeito artificial produzido por uma concepção de natureza humana em um sujeito submetido ao poder soberano, por meio de um procedimento central que orienta a relação de poder do nível mais elevado (o Estado) ao ponto mais atomizado (o indivíduo ontologicamente concebido).

Contrapondo-se a essa visão, Foucault (1999) pretende, ao invés de buscar entender os sujeitos a partir da instituição do "estado civil" ou da "civilizaçáo", traçar as linhas de dominação que perpassam a construção desses sujeitos. Sua pretensão é extrair empiricamente da história os operadores da dominação. Para o autor, ao contrário de partir de sujeitos pensados artificialmente por uma teoria da "natureza dos homens", deve-se buscar compreender como a relação de poder constrói os elementos sobre os quais incide.

A teoria da soberania pressupóe igualmente uma centralidade de poder. Segundo Foucault (1999), para essa teoria, a multiplicidade só pode funcionar dentro dos marcos de uma unidade do poder, de modo que há uma tendência a se "entificar" o poder, colocando-o em um local, como se pudesse irradiar do ente estatal. Seja na figura do Príncipe (Maquiavel), seja na força do Leviatá (Hobbes), seja na finalidade do Estado de garantir direitos (Locke) ou em sua forma (Rousseau), é dessa centralidade e unidade do poder que derivam todos os seus mecanismos e instituiçóes.

$\mathrm{Na}$ contramão dessa ideia de centralidade, Foucault (1999) sustenta que, de maneira oposta a se tentar criar um grande elemento de unidade da 
multiplicidade dos poderes, deve-se observá-los em suas próprias diversidades. Busca-se então partir das diferenças e não tentar unificá-los em uma razão ou intencionalidade central. Com isso, podemos nos deter mais em como cada operador da dominação se relaciona com os demais, de forma a sustentar uns aos outros, a fortalecerem e convergirem entre si, ou ainda, nos casos em que eles divergem, buscarem se anular.

Para Foucault (1999), a teoria da soberania busca mostrar não apenas como o poder emana da lei, mas também como deriva de uma espécie de "legitimidade fundamental". Nela, o "poder constitui-se não exatamente segundo a lei, mas segundo uma certa legitimidade fundamental, mais fundamental do que todas as leis, que é um tipo de lei geral de todas as leis e pode permitir às diferentes leis funcionarem como leis" (p. 50). Tal "legitimidade fundamental" é a condição de validade do direito positivo.

Foucault (1999) contesta a referida ideia de legitimidade e propóe o abandono dos alicerces que a sustentam. Para o autor, não é apropriado preocupar-se com a tentativa de justificar as razóes que permitem ao rei usar a coroa, mas sim deve-se buscar observar nos instrumentos de exercício de poder como os súditos se sujeitam, como é possível que haja um soberano, quais instrumentos técnicos dão sustentaçâo à ideia de legitimidade.

$\mathrm{Na}$ esteira da crítica à teoria da soberania, Foucault (1999) propóe que se troque a tríplice do "sujeito, unidade de poder e lei" pela "tríplice das técnicas, da heterogeneidade das técnicas e seus efeitos de sujeição, que fazem dos procedimentos de dominação a trama efetiva das relaçóes de poder e dos grandes aparelhos de poder" (p. 52). A partir de então, procura-se compreender as relaçóes de dominação como caminho de acesso à análise do poder. Ao tratar agora das relaçóes de dominação e não mais apenas de um poder soberano, pode-se começar a visualizar nas relaçóes de poder um forte elemento de força. O que se pretende dizer é que, de certa forma, as relaçóes de dominação são relaçóes de força. Desse modo, Foucault propóe o exame de como uma relação de força pode se resumir a uma relação de guerra. Ao evidenciar a trama dessas relaçôes, o autor pretende usar a guerra como elemento de intelecçáo da sociedade, analisando-a de forma antagônica aos discursos "filosófico-jurídicos" da soberania, de maneira a buscar entender precisamente o funcionamento de todas as relações e de todas as instituiçóes de poder. Assim, lança a pergunta:

Sob a paz, a ordem, a riqueza, a autoridade, sob a ordem calma das subordinaçóes, sob o Estado, sob os aparelhos do Estado, sob as leis, etc., devemos entender e redescobrir uma espécie de guerra primitiva e permanente? (Foucault, 1999, p. 53).

Foucault (1999), dessa forma, nega Maquiavel, para quem a capacidade de gerir os tumultos da plebe, de permitir que houvessem meios institucionais e regrados de lidar com as disputas, de ordenar os conflitos, de promover a manutenção de uma paz interna concebida enquanto equilíbrio dessas tensôes foi o que permitiu a solidificação de um império romano forte (Maquiavel volta sua análise para observar a estrutura institucional que permitiu tirar dos tumultos romanos a grandeza do império). Foucault nega também o pensamento contratualista de Hobbes, por interpretar o "estado da natureza" hobbesiano como não havendo batalhas, mas sim representações. Ou seja, a "guerra de todos contra todos" do "estado de natureza" de Hobbes se daria no plano das representaçóes, sem o confronto real das forças. Ademais, Foucault entende Hobbes como um filósofo da paz, e não da guerra, uma vez que para ele o soberano é instituído pelo pacto e deve ser forte justamente para impedir a guerra, para fazer cessar inclusive o perigo da guerra. Dessa forma, o Estado de Hobbes se funda exatamente por ser capaz de por termo à guerra e manter a paz.

Ao negar essas perspectivas que colocam o nascimento do Estado representando o armistício das forças em confronto, Foucault defende que "contrariamente ao que diz a teoria filosófico-jurídica, o poder político não começa quando cessa a guerra" (1999, p. 58). Com essa alegação, não se pretende negar que a guerra tenha presidido à fundação do Estado, mas sim, em verdade, busca-se sustentar que "o direito, a paz, as leis nasceram no sangue e nas lamas das batalhas" (Idem, Ibidem). Não se trata de batalhas ideais e disputas como imaginavam os teóricos da soberania, mas sim: 
Trata-se de redescobrir o sangue que secou nos códigos, e, por conseguinte, não, sob a fugacidade da história, o absoluto do direito: não reportar à relatividade da história ao absoluto da lei ou da verdade, mas, sob a estabilidade do direito, redescobrir o infinito da história, sob a fórmula da lei, os gritos de guerra, sob o equilíbrio da justiça, a dissimetria das forças (Idem, p. 66).

O surgimento do Estado, para Foucault, vem apenas como uma estratégia que modificou os termos dessa guerra. Porém, o confronto em si se mantém, é perpétuo, e se desenvolve silenciosamente obscurecido e mascarado por uma ordem legal e soberana que afirma insistentemente ter instituído a paz. É assim que o autor sustenta que "a lei não é pacificação, pois, sob a lei, a guerra continua a fazer estragos no interior de todos os mecanismos de poder, mesmo os mais regulares" (Idem, p.59).

O obscurecimento da guerra por meio da instituição de uma ordem legal é, para Bourdieu (1989), a expressão da lógica do funcionamento do campo jurídico, que procura funcionar como se fosse um a priori neutro e universal, mediante três efeitos: o de apriorização, o de neutralização e o de universalização. O efeito de apriorização combina elementos diretamente retirados da língua comum e elementos estranhos ao sistema, produzindo uma retórica da impersonalidade e da neutralidade, conferindo a aparência de fundamento transcendental às formas históricas da razão jurídica. É como se a lei sempre tivesse existido e não "pertencesse" a ninguém, a nenhum grupo social. O efeito de neutralização tem sentido próximo: constituir, mediante a formulação de construçóes passivas e frases impessoais, o enunciador em sujeito universal, aparentemente imparcial e normativo. $\mathrm{O}$ último efeito, o de universalizaçâo, também se obtém por meio da linguagem, por intermédio de vários processos convergentes:

[...] o recurso sistemático ao indicativo para enunciar normas, o emprego, próprio da retórica da atestação oficial e do auto, de verbos atestivos na terceira pessoa do singular do presente ou do passado composto que exprimem o aspecto realizado ("aceita", "confessa”, "compromete-se", "declarou" etc.); o uso de indefinidos ("todo o condenado") e do presente do intemporal - ou do futuro jurídico - próprios para exprimirem a generalidade e a omnitemporalidade da regra do direito: a referência a valores transubjectivos que pressupóem a existência de um consenso ético (por exemplo, "como bom pai de família"); o recurso a fórmulas lapidares e a formas fixas, deixando pouco lugar às variaçóes individuais (Idem, pp. 215-216).

A despeito dessa postura universalizante, para Bourdieu, a lei não tira o seu poder dela mesma, mas de uma série de dispositivos que, além de garantirem seu poder, dão a impressão de que esse poder emana apenas dela, isto é, faz com que ela pareça "necessária". Dessa forma, a lei é o resultado de um conjunto de relaçôes de força que contribuem para sua construção e consolidação, bem como de dispositivos que vão desde a linguagem como vimos nos três efeitos da escrita da lei - até suas práticas interpretativas: professores, juízes etc.

As reflexôes de Foucault e Bourdieu forçam-nos a reconhecer que tanto o direito quanto as leis (como "fontes do direito") não são isentos de relaçôes de dominação ou de força e, dessa forma, por detrás de uma suposta neutralidade jurídica, o direito e, principalmente as leis, são fruto de circunstancialidades políticas. Nesse sentido, o processo a partir do qual a lei se constituiu e reconstituiu continuamente, o "processo legislativo", deriva de relaçôes de força e de luta entre diversos atores sociais pelo monopólio do processo de formulação das leis. Conforme pondera Silva:

O processo legislativo é formal em dois sentidos. Primeiro, porque está subordinado a formalidades previstas na Constituição e nos regimentos internos das Câmaras Legislativas. Segundo, porque é representação (ou deve ser) do que, efetivamente, se dá no entrechoque dos interesses sociais. Por isso, quanto mais divergentes são os interesses das classes sociais, quanto mais são aguçadas as contradiçóes do sistema social vigente, tanto mais acirrados são os debates e as lutas no processo de formação das leis, já que estas vão estabelecer os limites 
dos interesses em jogo, tutelando uns e coibindo outros. Daí também a luta prévia relativa à composição dos órgãos incumbidos da função legislativa, pois que, no regime de representação popular e decisão por maioria, os titulares dos interesses que conseguirem maior representaçâo têm a possibilidade de domínio. Essa luta prévia se traduz no procurar evitar-se que os interesses dominados, ou que se quer dominar, venham a participar da legislação (Silva, 1964, pp. 27-28).

Além disso, a capacidade de formulação de tais leis depende de relaçóes de poder. Como destaca Becker (2008, pp. 29-30), as "diferenças na capacidade de fazer regras e aplicá-las a outras pessoas são essencialmente diferenciais de poder (seja legal ou extralegal)". Assim, no que tange especificamente à esfera legislativa, há a necessidade de refletirmos sobre os efeitos dos jogos de força política e das relações de poder exercidos na construção e desenvolvimento das leis. A melhor maneira de realizarmos tal proposição é desvelarmos as circunstancialidades ocultas na letra da lei, refletindo sobre os sentidos dados para ela por seus criadores e o contexto político, econômico e social em meio ao qual foi gestada. É somente ao analisarmos as forças políticas e as relações de poder ocultas e inerentes ao que chamaremos de construção legal-institucional da resolução negociada de conflito que compreenderemos apropriadamente o processo de expansão da legislaçáo no Brasil a partir dos anos de 1980. Antes de desenvolvermos tal proposta, faz-se necessário revelarmos nossa concepção de construção legal-institucional da resolução negociada de conflito.

\section{Quadro 1 \\ Métodos de Tratamento de Conflitos na Esfera Extrajudicial}

Arbitragem Procedimento no qual um ente ou júri supostamente neutro e imparcial encontra-se com as partes em conflito, ouve as apresentaçóes de cada lado e faz uma sentença ou uma decisão. Tal decisão pode ser aplicada nas partes se elas previamente concordarem com a mesma. Ao contrário do tribunal, as partes em disputa podem participar escolhendo o árbitro (que é com frequência um expert no assunto do conflito) e determinando as regras que governam o procedimento. Audiências de arbitragem sáo geralmente mantidas privadamente.

Fonte: Elaborado pelo autor com base em FAO (1998). 
A construção legal-institucional da resolução negociada de conflito

Entendemos por construção legal-institucional da resolução negociada de conflito o conjunto de iniciativas desenvolvidas na esfera legislativa voltadas para a criaçáo de leis visando disciplinar órgáos, métodos e instrumentos de tratamento dos conflitos na esfera extrajudicial, assim como alterar (via complementação ou revogaçáo) leis já existentes para atender ao mesmo objetivo. Tal reforma se dá na esteira de amplas mudanças na legislação do país, o que pode ser atribuído notadamente às reformas impostas por agendas políticas liberais inseridas em discursos de modernização e racionalização do Estado, compondo o que Schuch (2008) chamou de "paradigma técnico de 'modernização' da Justiça”.
Antes de identificarmos as iniciativas realizadas na esfera legislativa visando regulamentar órgãos, métodos e instrumentos extrajudiciais de tratamento dos conflitos, cabe aqui definirmos um pouco do repertório de procedimentos que consideramos como métodos de tratamento dos conflitos na esfera extrajudicial. ${ }^{7}$ Embora as definiçóes dos últimos não sejam consensuais, acreditamos que a identificação e descrição apresentadas no Quadro 1 forneçam um bom panorama.

Vale também definir alguns instrumentos de tratamento de conflito na esfera extrajudicial como o Termo de Ajustamento de Conduta (TAC), o Termo de Compromisso de Cessação de Prática (TCC) e Termo de Ajustamento de Gestão (TAG), conforme Quadro 2.

\section{Quadro 2}

\section{Instrumentos de Tratamento de Conflito na Esfera Extrajudicial}

\begin{tabular}{|c|c|}
\hline $\begin{array}{l}\text { Termo de } \\
\text { Ajustamento de } \\
\text { Conduta (TAC) }\end{array}$ & $\begin{array}{l}\text { Instrumento de tratamento de conflitos que tem como objeto a adequação do agir de um violador } \\
\text { ou potencial violador de um direito transindividual (direito difuso, coletivo ou individual } \\
\text { homogêneo) às exigências legais. Trata-se de uma espécie de acordo celebrado pelo Ministério } \\
\text { Público e por outros órgãos públicos com um violador ou potencial violador de um direito } \\
\text { transindividual que contém uma série de obrigaçáes (ou exigências) a serem cumpridas por este } \\
\text { violador ou potencial violador visando à reparação de dano a direitos transindividuais, à adequação } \\
\text { da conduta às exigências legais ou normativas e, ainda, à compensaçáo e/ou indenizaçáo por danos } \\
\text { que não possam ser recuperados. O TAC vale como título executivo extrajudicial e sua celebraçáo } \\
\text { possui influência na esfera civil. }\end{array}$ \\
\hline $\begin{array}{l}\text { Termo de } \\
\text { Compromisso } \\
\text { de Cessaçáo de } \\
\text { Prática (TCC) }\end{array}$ & $\begin{array}{l}\text { Instrumento de tratamento de conflitos envolvendo direitos transindividuais em risco diante de } \\
\text { determinadas práticas econômicas. Trata-se de uma espécie de acordo firmado entre o Conselho } \\
\text { Administrativo de Defesa Econômica (Cade) e qualquer pessoa natural ou jurídica, de natureza } \\
\text { pública ou privada, que esteja sendo investigada em processos administrativos de práticas lesivas } \\
\text { à ordem econômica (salvo os listados na Lei no } 10.149 \text {, de } 21 \text { de dezembro de 2000), negociando } \\
\text { a cessaçáo da conduta lesiva desta última à ordem econômica. O TCC vale como título executivo } \\
\text { extrajudicial e sua celebraçáo possui somente influência na esfera administrativa, de modo que não } \\
\text { pode elidir a aplicação de sanção civil de reparaçáo de danos ou de açáo penal. }\end{array}$ \\
\hline $\begin{array}{l}\text { Termo de } \\
\text { Ajustamento de } \\
\text { Gestáo (TAG) }\end{array}$ & $\begin{array}{l}\text { Instrumento pelo qual órgáos de controle como os Tribunais de Contas dos Estados (TCE) buscam } \\
\text { ajustar com os seus jurisdicionados novas práticas de gestão que visem corrigir, em determinado } \\
\text { prazo, irregularidades verificadas em denúncias ou processos administrativos. Trata-se de uma espécie } \\
\text { de acordo realizado na esfera da Administraçáo Pública entre o órgáo de controle e o gestor público } \\
\text { em que são definidas exigências e estipulados prazos para que o gestor cumpra as normas legais. }\end{array}$ \\
\hline
\end{tabular}

Fonte: Elaborado pelo autor com base em (Rodrigues 2000, 2002; Ferraz, 2011). 


\section{A criaçáo e a alteraçáo de leis no Brasil}

No Quadro 3, temos alguns exemplos de criação e alteração (via complementação ou revogação) de leis no Brasil, a partir da década de 1980, visando a regulamentação de órgãos da Justiça orientados para a atuação extrajudicial.

No Quadro 4, podemos ter uma dimensão da criação e alteração de leis visando promover a regulamentação de métodos extrajudiciais como a conciliação e a arbitragem e de instrumentos extrajudiciais na forma de títulos executivos extrajudiciais (o Termo de Ajustamento de Conduta - TAC, o Termo de Compromisso de Cessação de Prática - TCC e o Termo de Ajustamento de Gestão - TAG).

\section{Os “criadores de regras" (cruzados morais) e suas justificaçóes}

Partimos do pressuposto de que para entendermos uma regra devemos, antes de mais nada, compreender os objetivos e discursos que os criadores dessa regra possuíam ao formulá-la. Nesse sentido, para refletirmos sobre o processo de criação de leis visando disciplinar órgãos, métodos e instrumentos

\section{Quadro 3}

\section{Criação e Alteração (via Complementação ou Revogaçáo) de Leis no Brasil, a partir da Década de 1980, Visando a Regulamentaçáo de Órgáos da Justiça Orientados para a Atuaçáo Extrajudicial}

\begin{tabular}{ll}
\hline Lei $\mathrm{n}^{\circ} 7.244$, de 7 de & Dispóe sobre a criação e o \\
novembro de 1984 & funcionamento do Juizado
\end{tabular}

Especial de Pequenas Causas.
Em seu art. $2^{\circ}$, regulamenta que o processo, perante o Juizado Especial de Pequenas Causas, orientar-se-á pelos critérios da oralidade, simplicidade, informalidade, economia processual e celeridade, buscando sempre que possível a conciliação das partes. No art. 22, estabelecese que o juiz esclarecerá as partes sobre as vantagens da conciliação, mostrando-lhes os riscos e as consequências do litígio. $\mathrm{O}$ art. 25 prevê ainda a possibilidade de juízo arbitral caso não seja obtida a conciliação, por meio da escolha de um árbitro pelas partes.

\begin{tabular}{ll}
\hline Constituição Federal & Em seu preâmbulo, afirmam os \\
de 1988 & constituintes estarem instituindo, \\
& Dem a Constituição, um Estado \\
& uma série de valores supremos de \\
& uma "sociedade fraterna", "fundada \\
& na harmonia social" e \\
& comprometida, na ordem interna \\
& e internacional, com a "solução \\
& pacífica das controvérsias".
\end{tabular}

Lei $n^{\circ} 9.099$, de 16 de setembro de 1995
Dispóe sobre os Juizados Especiais Cíveis e Criminais e revoga, em seu art. 97, a Lei ${ }^{\circ}$ 7.244/84.
Em seu art. 24, inciso X, dispóe que compete à União, aos Estados e ao Distrito Federal legislar concorrentemente sobre a criação, funcionamento e processo do juizado de pequenas causas. Já no art. 98, inciso I, estabelece que a União, no Distrito Federal e nos Territórios, e os Estados criarão juizados especiais, providos por juízes togados, ou togados e leigos, competentes para a conciliaçáo, o julgamento e a execução de causas cíveis de menor complexidade e infraçôes penais de menor potencial ofensivo. ${ }^{8}$

Em seu art. $3^{\circ}$, estabelece que o Juizado Especial Cível tem competência para conciliaçáo, processo e julgamento das causas cíveis de menor complexidade. O inciso II do parágrafo $1^{\circ}$ deste art. $3^{\circ}$, dispóe que compete ao Juizado Especial promover a execuçáo de títulos executivos extrajudiciais, no valor de até quarenta vezes o salário mínimo. 


\section{Quadro 4 \\ Criação e Alteração de Leis Visando Promover a Regulamentaçáo de Métodos Extrajudiciais}

\begin{tabular}{ll}
\hline Lei no 8.069 , de 13 de & $\begin{array}{l}\text { Dispóe sobre o Estatuto da Criança } \\
\text { julho de } 1990\end{array}$ \\
\end{tabular}

TAC em seu art. 211.
Estabelece que os órgãos públicos legitimados poderão tomar dos interessados compromisso de ajustamento de sua conduta às exigências legais, o qual terá eficácia de título executivo extrajudicial.

Estabelece que os órgáos públicos legitimados poderão tomar dos interessados compromisso de ajustamento de sua conduta às exigências legais, mediante combinações, que terá eficácia de título executivo extrajudicial.

\begin{tabular}{|c|c|}
\hline $\begin{array}{l}\text { Lei } \mathrm{n}^{\circ} 8.884 \text {, de } 11 \\
\text { de junho de } 1994 \\
\text { (posteriormente revogada } \\
\text { pela Lei }{ }^{\circ} 12.529 \text {, de } 30 \\
\text { de novembro de } 2011 \text { ) }\end{array}$ & $\begin{array}{l}\text { Transforma o Conselho } \\
\text { Administrativo de Defesa Econômica } \\
\text { (Cade) em autarquia, dispóe sobre a } \\
\text { prevenção e a repressão às infraçóes } \\
\text { contra a ordem econômica. Prevê } \\
\text { a possibilidade de compromisso de } \\
\text { cessação de atividades de empresa } \\
\text { investigada por infraçáo à ordem } \\
\text { econômica. }\end{array}$ \\
\hline
\end{tabular}

Lei $n^{\circ} 9.099$, de 26 de Revoga a Lei no 4.611, de 2 de abril setembro de 1995 de 1965 e a Lei no 7.244 , de 7 de novembro de $1984 \mathrm{e}$, em seu art. 57, prevê a possibilidade de acordo extrajudicial.
Em seu art. $7^{\circ}$, aprova o uso de termos do compromisso de cessaçáo de prática e do compromisso de desempenho. No art. 85 da Lei $\mathrm{n}^{\circ} 12.529 / 00$, consta que o termo de compromisso de cessação de prática constitui título executivo extrajudicial

\begin{abstract}
Dispõe, no parágrafo único do art. 57 , que valerá como título extrajudicial o acordo celebrado pelas partes, por instrumento escrito, referendado pelo órgão competente do Ministério Público.
\end{abstract}

Lei ${ }^{\circ} 9.307$, de 23 de setembro de 1996

\section{Dispóe sobre a arbitragem e, no $₫ 2^{\circ}$} do art. $9^{\circ}$, prevê a possibilidade de compromisso arbitral extrajudicial.
Dispõe, no parágrafo único do art. $11^{\circ}$ que, fixando as partes os honorários do árbitro, ou dos árbitros, no compromisso arbitral, este constituirá título executivo extrajudicial.
Lei $n^{\circ} 9.958$, de 12 de janeiro de 2000
Altera e acrescenta artigos à

Consolidação das Leis do Trabalho (CLT), dispondo sobre as Comissões de Conciliação Prévia e permitindo a execução de título executivo extrajudicial na Justiça do Trabalho.

\begin{tabular}{ll}
\hline Lei Estadual (Rio de & $\begin{array}{l}\text { Dispóe sobre sançóes administrativas } \\
\text { Janeiro) } \mathrm{n}^{\circ} 3.467, \text { de } 14\end{array}$ \\
derivadas de condutas lesivas ao \\
meio ambiente e, em seu art. 101, \\
estabelece o termo de compromisso \\
ou de ajuste ambiental.
\end{tabular}

Medida Provisória $\mathrm{n}^{\mathrm{o}}$

2.163-41, de 23 de agosto de 2001

\section{Acrescenta o art. 79-A à Lei n ${ }^{\circ}$}

9.605, de 12 de fevereiro de 1998, a

Lei de Crimes Ambientais
Permite a execuçáo do termo de conciliação, um título executivo extrajudicial na Justiça do Trabalho. No parágrafo único do art. 625-E, consta que o termo de conciliação é um título executivo extrajudicial, que possui eficácia liberatória geral.

Possibilita que as multas aplicadas com base nesta lei possam ter a sua exigibilidade suspensa mediante a celebração de termo de compromisso ou de ajuste ambiental, com força de título executivo extrajudicial.

Permite que os órgãos ambientais integrantes do Sisnama, responsáveis pela execução de programas e projetos e pelo controle e fiscalizaçáo dos estabelecimentos e das atividades suscetíveis de degradarem a qualidade ambiental, celebrem, com força de título executivo extrajudicial, termo de compromisso. 


\section{Quadro 4 (continuaçáo) \\ Criação e Alteração de Leis Visando Promover a Regulamentaçáo de Métodos Extrajudiciais}

\section{Medida Provisória no}

131, de 25 de setembro de 2003 (convertida na

Lei 10.814 , de 15 de

dezembro de 2003)
Estabelece normas para o plantio e comercialização da produção de soja da safra de 2004.
Estabelece o Termo de Compromisso, Responsabilidade e Ajustamento de Conduta, que terá eficácia de título executivo extrajudicial na forma dos art. $5^{\circ}, \$ 6^{\circ}$, da Lei $n^{\circ} 7.347$, de 24 de julho de 1985, e 585, inciso VII, do Código de Processo Civil.
Decreto Municipal (Belo Dispóe sobre procedimentos de Horizonte) $\mathrm{n}^{\circ} 12.634$, de controle interno no âmbito da 22 de fevereiro de 2007
Administração Direta e Indireta do Município de Belo Horizonte e dá outras providências.
No art. 11, II, estabelece possibilidade de celebração de Termo de Compromisso de Gestão - TCG na hipótese de constatação de irregularidades Administração Direta e Indireta do Município de Belo Horizonte. No art. 12, afirma-se que o Termo de Compromisso de Gestão - TCG é instrumento de controle consensual, celebrado entre a autoridade máxima do órgão, entidade, programa ou projeto auditado e a Controladoria-Geral do Município. ${ }^{9}$

$\begin{array}{ll}\text { Lei no } 13.105, \text { de } 16 \text { de } & \text { Regulamenta o novo Código de } \\ \text { março de } 2015 & \text { Processo Civil. }\end{array}$

Lei no 13.140 , de 26 de Dispóe sobre a mediação. junho de 2015
Em seu art. $3^{\circ}$ preconiza o uso da conciliação, mediação e outros métodos de solução consensual de conflitos

\section{Dispóe sobre a mediação entre particulares como meio de solução de controvérsias e sobre a autocomposição de conflitos no âmbito da administração pública.}

\begin{tabular}{ll}
\hline Instrução Normativa & Disciplina a celebração do Termo de \\
$n^{\circ} 2$, de 30 de maio de & Ajustamento de Conduta (TAC), no \\
2017 & âmbito do Poder Executivo Federal.
\end{tabular}
$\mathrm{n}^{\circ} 2$, de 30 de maio de
Em seu art. 1\%, dispóe que os órgáos e entidades do Poder Executivo Federal poderão celebrar, nos casos de infração disciplinar de menor potencial ofensivo, Termo de Ajustamento de Conduta (TAC), desde que atendidos os requisitos previstos nesta instruçáo normativa.

Lei no 13.467 , de 13 de Altera a Consolidação das Leis do julho de 2017 Trabalho (CLT).
Insere o capítulo III-A, que dispóe sobre o processo de jurisdição voluntária para homologação de acordo extrajudicial no âmbito trabalhista.

\begin{tabular}{ll}
\hline Instrução Normativa no & Dispóe sobre a celebração de Termo \\
078 , de 9 de outubro de & $\begin{array}{l}\text { de Ajustamento de Conduta (TAC) } \\
\text { no âmbito do Instituto Nacional da } \\
\text { Propriedade Industrial (INPI). }\end{array}$
\end{tabular}

Instrução Normativa no 078, de 9 de outubro de Propriedade Industrial (INPI).
Em seu art. $1^{\circ}$, afirma-se que a Corregedoria do INPI poderá celebrar, exclusivamente nos casos de infração disciplinar de menor potencial ofensivo, Termo de Ajustamento de Conduta (TAC), desde que atendidos os requisitos previstos nesta instrução normativa.

Fonte: Elaborado pelo autor com base na legislaçáo brasileira. 
de tratamento dos conflitos na esfera extrajudicial (a construção legal-institucional da resolução negociada de conflito), necessitamos identificar seus "criadores" e suas bases de justificação. Para tanto, temos em mente a assertiva de Becker sobre tais atores sociais:

O protótipo do criador de regras, mas não a única variedade, como veremos, é o reformador cruzado. Ele está interessado no conteúdo das regras. As existentes não o satisfazem porque há algum mal que o perturba profundamente. Ele julga que nada pode estar certo no mundo até que se façam regras para corrigi-lo. Opera com uma ética absoluta; o que vê é total e verdadeiramente mal sem nenhuma qualificação. Qualquer meio é válido para extirpá-lo (Becker, 2008, p. 153).

Acrescenta ainda o autor que:

Cruzados morais querem, de modo típico, ajudar os que estão abaixo deles a alcançar um melhor status. Outra questão é saber se os que estão abaixo deles gostam sempre dos meios propostos para sua salvação. Mas esse fato - que as cruzadas morais são em geral dominadas por aqueles situados nos níveis superiores da estrutura social significa que eles acrescentam ao poder que extraem da legitimidade de sua posição moral o poder que extraem de sua posição superior na sociedade (Idem, pp. 154-155).

No que diz respeito à busca pela criação de órgãos de justiça voltados para tratar conflitos na esfera extrajudicial, o anteprojeto de lei referente ao Juizado Especial de Pequenas Causas (Lei n ${ }^{\circ}$ 7.244, de 7 de novembro de 1984), por exemplo, foi elaborado durante o governo militar de João Figueiredo pelo Programa Nacional de Desburocratizaçáo. Este programa tinha como um de seus objetivos:

[...] reduzir a interferência do Governo na atividade do cidadão e do empresário e abreviar a solução dos casos em que essa interferência é necessária, mediante a descentralização das decisões, a simplificação do trabalho adminis- trativo e a eliminação de formalidades e exigências cujo custo econômico ou social seja superior ao risco (Art. $3^{\circ}$ do Decreto no 83.740, de 18 de julho de 1979).

Nos moldes da busca pela superação de formas "burocráticas" de administração do Estado e de sua "modernização" e "racionalização", foram estabelecidos como princípios básicos dos juizados: facultatividade; busca permanente de conciliação; simplicidade; celeridade; economia; amplitude dos poderes do juiz.

Ao fazer a exposição de motivos da Lei do Juizado Especial de Pequenas Causas, o então Ministro da Desburocratização e coordenador do Programa Nacional de Desburocratização, Hélio Beltrão, sustenta que:

O alto custo da demanda, a lentidão e a quase-certeza da inviabilidade ou inutilidade do ingresso em Juízo são fatores restritivos, cuja eliminação constitui a base fundamental da criação do novo procedimento judicial e do próprio órgão encarregado de sua aplicação, qual seja o Juizado Especial de Pequenas Causas. ${ }^{10}$

No que tange à busca pela criação de métodos extrajudiciais, a Lei $\mathrm{n}^{\circ}$ 9.307, de 23 de setembro de 1996, que dispóe sobre a arbitragem, surge no governo Fernando Henrique Cardoso (FHC), que levou adiante e aprofundou a política neoliberal iniciada por seu antecessor, Fernando Collor de Mello, adensando processos de privatização, desregulamentação e abertura econômica.

Para promover a reforma do Estado, o governo FHC articulou medidas legislativas, mudança regulatória e ações governamentais para uma reordenação estratégica de seu papel, sob a justificativa de impulsionador o desenvolvimento e a competitividade da economia. Em seu Plano Diretor da Reforma do Aparelho do Estado (elaborado pelo Ministério da Administração Federal e da Reforma do Estado e, depois de ampla discussão, aprovado pela Câmara da Reforma do Estado, em sua reunião de 21 de setembro de 1995), o governo já anunciava sua pretensão de empreender uma reforma legislativa: "acompanhando a reforma constitucional será neces- 
sário aprovar no Congresso toda uma nova legislação infraconstitucional" (Câmara..., 1995, p.50).

A Lei da Arbitragem é o resultado de um esforço empreendido pelo então senador Marco Maciel que, em 3 de junho de 1992, em solenidade no Senado Federal, formulou e encaminhou à apreciação do Congresso Nacional o Projeto de Lei $n^{\circ} 78 / 92$. Tal projeto surge um ano após e sob influência da criação do Mercado Comum do Sul (Mercosul), criado em 26 de março de 1991, que unia Brasil, Argentina, Paraguai e Uruguai em um mesmo bloco econômico. O Mercosul previa, em seu art. 3 e no anexo III, a adoção de um sistema de solução de controvérsias, regulamentado pelo Protocolo de Brasília, de 17 de dezembro de 1991. Nesse sistema, estipula-se que os Estados-partes, numa controvérsia, procurarão resolvê-la, antes de tudo, mediante negociações diretas (art. 2). Não se alcançando um acordo ou se a controvérsia for solucionada apenas parcialmente, os Estados-partes podem submetê-la à consideração do Grupo Mercado Comum (GMC), que avaliará a situação, propiciando oportunidades às partes para que exponham suas respectivas posiçóes e requerendo, quando necessário, o assessoramento de especialistas. Caso não seja solucionada a controvérsia, qualquer um dos Estados-partes pode comunicar à Secretaria Administrativa sua intençáo de recorrer ao procedimento arbitral, constante no capítulo IV (intitulado "Procedimento arbitral”) do Protocolo de Brasília.

A Lei da Arbitragem, que levou a alcunha de "Lei Maciel”, é considerada pelos doutrinadores do direito como um sistema monista, vez que não faz distinção entre a arbitragem estrangeira e a arbitragem internacional, ${ }^{11}$ servindo tanto para dirimir questóes de foro nacional quanto internacional. Sancionada durante o governo FHC, no qual Marco Maciel assume o posto de vice-presidente da República, a referida lei insere-se na plataforma da política neoliberal do governo, que postulava uma modernização e racionalização do Estado na busca de superar de formas "burocráticas" de administrá-lo, bem como no intuito de delimitar sua intervenção no funcionamento do mercado. Marco Maciel apresenta suas pretensôes de criar, com a edição dessa lei, um mecanismo que, ao operar fora da área judiciária, agilizasse a "solução" conflitos:
A Lei 9.307, sancionada no ano passado pelo presidente Fernando Henrique Cardoso, originária de projeto de minha autoria, aprovado à unanimidade pelo Senado Federal e por ampla maioria na Câmara dos Deputados, significa, por consequência, um avanço considerável nos caminhos de emancipação da sociedade, além de contribuir significativamente para amenizar a carga de trabalho, crescente em progressão geométrica, que ameaça inviabilizar o funcionamento da Justiça dos Tribunais Superiores, se medidas adequadas não forem prontamente adotadas. A grande parte dos processos na área civil e a quase totalidade das questóes comerciais que envolvem interesses e recursos econômicos relevantes podem encontrar, nessa via, o caminho de uma solução natural, consensuada e de enorme praticidade, desde que, como já está começando a ocorrer, sejam criados, sem interferência do Estado, mecanismos e instituiçóes capazes de agilizar conflitos que, na área judiciária, podem levar anos para ser solucionados (Maciel, 1997, pp. 3-4, grifos nossos).

Além das pretensões notadamente voltadas para a desjudicialização e busca por agilidade na "solução" dos conflitos na área civil envolvendo questóes comerciais, apela-se também para a criação de mecanismos "inovadores" que trouxessem "consenso" e "soluçóes pacíficas" para os conflitos. Nas palavras de Maciel:

Os mecanismos institucionais decorrentes de todas essas inovaçôes têm por finalidade normatizar as práticas usuais da politica, valorizando a conciliação, a busca do consenso e a solução pacífica dos conflitos, garantidoras de um lado da coesáo social e da legitimidade, e de outro, da própria governabilidade. Com a evolução natural da experiência que vai sendo, metodicamente, acumulada, criam-se novos e inéditos canais de articulação entre as instituiçóes públicas cada vez mais mobilizadas pelo imperativo da eficácia [...]. Inclui-se, nessa linha de atuação, o instituto jurídico da arbitragem, que não é novo em nosso direito positivo legislado, uma vez que era já previsto no Código Civil, em vigor 
desde 1917, mas que permaneceu como letra morta nas práticas jurídicas brasileiras (Idem, p. 2, grifos nossos).

A busca pelo "consenso" integra igualmente as pretensões do advogado e consultor Luciano Ferraz ao idealizar o instrumento extrajudicial Termo de Ajustamento de Gestão (TAG) como instrumento de controle da Administração Pública. Segundo o autor:

O abalo do modelo burocrático de administração reclama formas menos rígidas de atuação, numa onda de resgate da colaboração entre Estado, sociedade e indivíduos. Em tempos hodiernos, a imperatividade cede espaço à consensualidade. Fala-se mesmo em "era da consensualidade”. Assim é que se propõe a existência de um princípio da consensualidade a impor à Administração Pública o dever de, sempre que possível, buscar a solução para as questôes jurídicas e conflitos que vivencia pela via do consenso (Ferraz, 2011, p. 3, grifos nossos).

Nesse tocante, afirma ainda que:

As conclusões alcançadas levaram-me a propor modelo de controle da atividade administrativa baseado no consenso e não na sanção [...] vislumbrei a possibilidade de utilização pelos Tribunais de Contas e pelos órgãos de controle interno de instrumentos alternativos de controle, baseados na consensualidade, ao invés de na imperatividade. Primeiramente, para o âmbito das Cortes de Contas, nominei esses instrumentos de controle de TACTC (Termos de Ajustamento de Conduta dos Tribunais de Contas). Ao depois, em palestra proferida no Tribunal de Contas do Município do Rio de Janeiro, no dia 19.08.2005, passei a denominá-los, mais apropriadamente, Termos de Ajustamento de Gestão (TAG) (Idem, pp. 1-2, grifos nossos).

A partir de então, por questóes econômicas, por uma série de fatores ligados à inflação de demandas judiciais e pela intenção de estabelecer novas formas de tratamento dos conflitos, tais cruza- dos morais criam a expectativa de que os órgãos, métodos e instrumentos extrajudiciais venham a trazer novas formas de pacificação social.

\section{A busca pela reconfiguraçáo da funçáo "pacificadora" do Estado de tratamento dos conflitos sociais}

Por "novas formas de pacificação social”, não queremos passar a ideia de que tais métodos e instrumentos sejam novos no âmbito do direito ou na história da sociedade. De fato, como afirmam certos estudiosos, antes mesmo do Estado conquistar para si o poder de declarar qual o direito no caso concreto e promover a realização de sua prática mediante a jurisdiçáo, métodos como a arbitragem já existiam. ${ }^{12} \mathrm{O}$ que consideramos como nova é a busca pela reconfiguração da função tradicional do Estado em seu objetivo de tratar os conflitos, que envolve todo um discurso de justificação da via extrajudicial como forma de tornar mais "pacífico", "consensual" e "célere" o tratamento dos conflitos. Cria-se agora a expectativa de que a desjudicializaçáo do tratamento dos conflitos mediante o uso de métodos e instrumentos extrajudiciais contribua para a obtenção da pacificação da sociedade, ao identificar a via extrajudicial como uma forma de se obter um tratamento negociado e acordado para os conflitos, em contraposição às decisóes impostas por sentenças judiciais, ou seja, como forma de se evitar "o comando frio e enérgico de uma sentença" (De Mio, 2005 , p. 28). Busca-se, dessa forma, "soluçôes pacíficas" que se deem em contraposição ao uso do direito como "forma regulamentada de fazer a guerra” (Foucault, 2011, pp. 56-57).

$\mathrm{Na}$ literatura do direito, por exemplo, encontramos as seguintes mençóes ao aspecto da pacificação no que concerne o Termo de Ajustamento de Conduta:

[...] o termo de ajustamento de conduta mostra-se um forte aliado, contribuindo para a $p a-$ cificação social sem as consequências, nem sempre positivas, da lide (Coutinho, 2006, p. 428, grifos nossos). 
Em suma, o compromisso de ajustamento de conduta, conquanto ainda não tenha alcançado toda sua potencialidade, assim mesmo já é um grande avanço na composição extrajudicial de conflitos coletivos (de grupos, classes ou categoria de pessoas), e, assim, torna mais eficaz a defesa de interesses transindividuais. Desta forma, concorre grandemente para a obtenção da harmonia e paz social (Mazzilli, 2006, p. 19, grifos nossos).

Nesse caso, como afirma Nader (1996), a busca por "soluçóes" pacificadas para os conflitos - o que a autora chamou de "ideologia da harmonia" -, transforma a "ética do certo e errado" em "ética do tratamento". Nader, em sua análise da retórica da resolução alternativa de disputa (Alternative Dispute Resolution - ADR), descreve esse processo:

Comecei a coletar palavras-chave: a ADR estava associada à paz, enquanto a solução mediante disputa judicial era relacionada à guerra. Uma é antagônica, a outra não antagônica. Em uma há confronto, insensibilidade, destruição da confiança e da cooperação, e apenas perdedores, enquanto na outra a cura suave e sensível dos conflitos humanos produz apenas vencedores (Nader, 1996, p. 49).

A reconfiguração da função tradicional do Estado em seu objetivo de tratar os conflitos envolve, como sustenta Sadek (2004), a busca por uma nova mentalidade nos operadores do direito, mais aberta e menos formalista, principalmente nos juízes, serventuários da Justiça, advogados, procuradores e promotores, substituindo a postura de árbitro, em um jogo de soma zero, por uma de pacificação, em uma arena de composiçóes e acertos. No bojo dessa dinâmica, há todo um esforço no sentido de se criar novas arenas de tratamento de conflito, como é o caso dos Juizados Especiais, bem como há toda uma procura por recaracterizar instituiçôes vinculadas às arenas tradicionais de tratamento de conflito como, por exemplo, o Ministério Público. Enxerga-se, nessa dinâmica, a "evolução" do direito e do Estado em sua função privilegiada de "manutenção da paz e ordem social":
Promover os Juizados Especiais faz parte desta evolução. Implementar em seu seio práticas processuais inovadoras e participativas torna a caminhada frutífera. Etapas do procedimento são queimadas. Enxerga-se a problemática por trás da causa. As partes se sentem mais honradas. Tornam-se mais cientes de suas açóes. Gera-se comprometimento e aceitação. Há menos inconformismo. Têm-se uma visão clara dos interesses em julgamento. Crer em novas formas de pacificação social traz, em verdade, a certeza de que náo estamos paralisados. Criatividade é a palavra. Ativistas sim, atávicos nunca (Vidal, 2008, p. 3).

Ao se criar um apelo e expectativa de tal avanço "evolutivo" mediante o uso de métodos de tratamento de conflito que remontam a períodos que antecedem o surgimento do Estado - ou ainda para o uso de métodos que, como afirma Maciel (1997), permaneceram como letra morta nas práticas jurídicas brasileiras -, parte-se da ideia de que "função estatal pacificadora" mediante a jurisdição não foi suficiente para dar conta, em número e grau, da totalidade dos conflitos provenientes da vida em sociedade. Diante disso, espera-se que a construção legal-institucional da resolução negociada de conflito, por meio da criação de instituiçôes e mecanismos - extrajudiciais em grande parte - constitua esforços no enfrentamento de tal insuficiência ao melhor processar as demandas judiciais ou mesmo preveni-las.

\section{Consideraçóes finais}

Ao identificarmos as iniciativas realizadas na esfera legislativa para o desenvolvimento da reforma do sistema de justiça, consubstancializadas pelo processo que denominamos de construção legal-institucional da resolução negociada de conflito, buscamos evidenciar este processo como o resultado do esforço de certos "criadores de regras" por reconfigurar o que se entende por função "pacificadora" do Estado de tratar os conflitos. Tais "criadores de regras" justificam a formulação de leis visando disciplinar órgãos, métodos e instrumentos de tratamento dos conflitos na esfera extrajudicial por 
meio de discursos que reforçam a via extrajudicial como a maneira de tornar mais "pacífico", "consensual" e "célere" o tratamento dos conflitos, em contraposição aos procedimentos desenvolvidos na esfera judicial - considerada conflituosa, rígida, imperativa e morosa.

Entretanto, uma reflexão acerca da validade de tais justificativas na prática do sistema de justiça brasileiro é imprescindível. No que se refere à celeridade, cabe aqui retomar a advertência de Cappelletti e Garth (1988) sobre os riscos que a pressão sobre o sistema judiciário (por reduzir sua carga e encontrar procedimentos menos onerosos e mais céleres) pode acarretar nos critérios de justiça, ao "subverter os fundamentos de um procedimento justo" e obscurecer o foco do acesso à justiça, colocando em jogo, dessa forma, a "morosidade necessária" (Sousa Santos, Marques e Pedroso, 1996) para esse procedimento - o tempo ideal de duração do tratamento de conflito que concilie rapidez e eficiência com proteção de direitos. Um exemplo de sobrevalorizaçáo do aspecto da celeridade na aplicação de instrumentos extrajudiciais fica expresso na afirmação de Cappelli sobre o Termo de Ajustamento de Conduta: "tal solução extrajudicial, além de mais célere e, portanto, mais eficaz, póe a lume a importância politico-institucional do Ministério Público e propicia, diretamente, o conhecimento dos problemas, sua investigação e deslinde" (2002, p. 233, grifos nossos). Em tal afirmação, aponta-se o princípio da eficácia como uma consequência direta da celeridade, como se ser mais rápido fosse necessariamente ser mais eficaz. Nesse sentido, vale salientar a observação de Alemão e Barroso de que:

Hoje, quando nos debruçamos sobre a instituição judiciária, os maiores apelos que vemos são quanto à celeridade, à duração razoável do processo. Aliás, essa preocupação aumentou com a facilidade que se tem em medir o grau de rapidez de um processo, pois a contagem é facilmente feita por anos e dias. Assim, os avanços tecnológicos de informática facilmente revelam o grau de morosidade de um órgão judicial. O mesmo não ocorre com a justiça em seu sentido de direito, de equidade, de razão e de conquistas (Alemão e Barroso, 2011, p. 5).
Complementam ainda os autores:

As noções de eficiência, celeridade, de direito e de justiça, precisam ser compreendidas e consideradas de modo a não comprometer as atribuições específicas do próprio sistema judiciário. Achar uma justa e adequada medida, eis o grande desafio (Idem, p. 3).

No que tange às justificativas de "pacificação" e "consenso", podemos afirmar que tais discursos surgem no contexto do que Rancière (1996) denomina por "pós-democracia consensual", caracterizada pela passagem da ênfase no conflito para o consenso, principalmente a partir dos anos de $1990^{13}$ (Lautier, 2010). Se concebermos, como Mouffe (1996), a constituição das noções de direito, de justiça, de sociedade bem ordenada e mesmo a construçáo de consenso como construçóes discursivas sempre contingentes e precárias, o consenso pode ser considerado como um arranjo histórico e contingente, fruto de um tipo de formulação política que busca hegemonizar seus conteúdos socialmente e, nesse sentido, em sua proposta de abranger a todos os interesses, pode ser o resultado de uma imposição política excludente que desconsidera outras formas de tomada de decisão, outras maneiras de conceber o jogo democrático, uma vez que as relega à condição de formulaçôes políticas inferiores. Assim, ao se buscar instrumentos "consensuais", pode-se perder o foco da busca por "procedimentos justos" (Cappelletti e Garth, 1988). Acselrad, Bezerra e Gaviria reconhecem esse processo ao afirmarem que:

É fácil perceber essa ocorrência, por exemplo, no caso brasileiro, com relação aos Termos de Ajustamento de Conduta (TACs), que são usualmente simbolizados enquanto formas de se obter o 'consenso', à maneira de 'Termos de acordo', e não de instrumento de garantia da legislação e de concepçôes de justiça social (Acselrad, Bezerra e Gaviria, 2010, p. 23).

A busca pelo consenso pode ampliar desequilíbrios de poder e dar margem para a coerção e manipulação por parte das partes mais fortes. Portanto, métodos como a mediação podem pro- 
duzir resultados injustos, isto é, produzir resultados de maneira desproporcionada e injustificadamente favorável às partes mais fortes. Pela sua informalidade, a mediação pode fornecer aos mediadores um amplo poder estratégico para controlar a discussão, o que favorece qualquer tipo de bias por parte dos mesmos. Tal bias pode afetar a seleção e elaboração das questôes, a apreciação e classificação das opçôes de solução do problema, bem como em vários outros elementos que influenciam os resultados.

Não obstante a extensão das iniciativas realizadas na esfera legislativa para a realização da reforma do sistema de justiça, pouca evidência sistemática foi reunida sobre os órgãos de atuação extrajudicial e sobre o uso dos métodos e instrumentos extrajudiciais de tratamento dos conflitos. Os resultados da construção legal-institucional da resolução negociada de conflito continuam abertos ao debate e dados descritivos amplos sobre essa construção são escassos. Essa realidade chama a atenção para a necessidade de exame de todo processo de tomada de decisão na esfera extrajudicial sobre as possíveis "soluçôes" para os problemas e conflitos em sociedade.

\section{Notas}

1 No presente artigo, à semelhança de Little (2001) em sua crítica às ideias de "solução" dos conflitos socioambientais, consideramos ser mais realista falar em "tratamento" do conflito em vez de sua "solução", expressão corrente na literatura do direito. Com isso, salientamos a dificuldade de qualquer método ou instrumento regulamentado (judicial ou extrajudicial) suprimir ou eliminar as causas, tensóes e contrastes que originaram o conflito, de maneira a abranger em sua totalidade a complexidade e profundidade das divergências existentes entre as partes em conflito.

2 Cappelletti e Garth (1988) afirmam que o despertar do interesse ao acesso efetivo à justiça levou a três tipos de “ondas' de reforma que emergiram, a partir do ano de 1965, em sequência cronológica nos países do mundo ocidental. A primeira "onda" desse movimento foi a assistência judiciária, que focou em proporcionar serviços jurídicos para os pobres. Essa primeira "onda" foi seguida por uma segunda, referente às reformas realizadas com vistas a garantir representação jurídica para os interesses "difusos", especialmente nas áreas de proteção ambiental e do consumidor. A ter- ceira e mais recente "onda", denominada pelos autores de "enfoque de acesso à justiça", representa uma tentativa de atacar as barreiras ao acesso à Justiça de modo mais articulado e compreensivo e de enfrentar a inflação de demandas judiciais. Essa terceira "onda”, ainda que incluindo as soluçóes e posicionamentos das "ondas" anteriores, centra sua atenção na criação de instituiçôes e mecanismos - extrajudiciais em grande parte-como forma de melhor processar e mesmo prevenir disputas nas sociedades modernas. Dentro dessa recente "onda" de enfoque de acesso à justiça, podemos inserir diferentes modelos de alteração dos procedimentos entáo correntes do sistema de justiça, tais como os modelos de "justiça informal" e de "justiça restaurativa”. Vale destacar que, com o passar do tempo, essa "onda" deixa de ser exclusiva dos países ocidentais e se estende para os países orientais. Exemplo disso é o modelo de "justiça tradicional" do Timor-Leste. Neste último, o termo "tradicional” é utilizado para abarcar as formas de justiça calcadas em procedimentos extrajudiciais (Simião, 2007).

3 Fala de abertura do seminário "Poder Judiciário e arbitragem: diálogo necessário”, realizado no Supremo Tribunal Federal (STF), no dia 27 de abril de 2011. Disponível em http://www2.trf4.jus.br/trf4/upload/ editor/rbb_Ministra\%20ellen\%201.pdf., consultado em 25/07/2018.

4 Nesse aspecto, afastamo-nos da perspectiva de Sadek (2004), para quem, no plano das propostas de reforma extrajudicial do judiciário, o Brasil buscaria acompanhar uma tendência mundial no sentido de promover um enxugamento da legislação. Ao contrário do sustentado pela autora, reconhecemos como resultado das propostas de reforma extrajudicial na esfera legislativa uma expansão da legislação, mediante a criação de leis voltadas para regulamentar órgãos, métodos e instrumentos de tratamento dos conflitos na esfera extrajudicial, assim como alterar (via complementação ou revogação) leis já existentes.

5 A definição da autotutela (ou autodefesa) como crime quando praticada pelo particular pode ser encontrada no Código Penal brasileiro em seu art. 345, que define o "exercício arbitrário das próprias razóes".

6 A definição da autotutela (ou autodefesa) como crime quando praticada pelo Estado pode ser encontrada no Código Penal brasileiro em seu art. 350, que define o "exercício arbitrário ou abuso de poder".

7 Encontraremos inúmeras outras denominaçóes na literatura do direito para o que consideramos por métodos de tratamento dos conflitos na esfera extra- 
judicial. Alguns exemplos são: "métodos não adversariais de conflito", "métodos alternativos de solução de conflito", "meios não convencionais de atividade jurisdicional", "sucedâneos da jurisdição" etc.

8 Alguns exemplos da introdução do sistema de juizados especiais nos estados são: Lei $n^{\circ} 1.071$, de 11 de julho de 1990 (Mato Grosso do Sul); Lei n ${ }^{\circ} 1.141$, de 25 de março de 1993 (Santa Catarina); Lei n ${ }^{\circ}$ 6.845, de 27 de dezembro de 1995 (Rio Grande do Norte); Lei $\mathrm{n}^{\circ}$ 10.675, de 2 de janeiro de 1996 (Rio Grande do Sul); Lei n ${ }^{\circ} 2.556$, de 21 de maio de 1996 (Rio de Janeiro); Lei n ${ }^{\circ}$ 656, de 22 de maio de 1996 (Rondônia); Lei n ${ }^{\circ} 820$, de 30 de janeiro de 1996 (Tocantins); Lei Complementar no 851, de 9 de dezembro de 1998 (São Paulo).

9 Segundo Ferraz (2011), o Termo de Ajustamento de Gestấo (TAG) foi pioneiramente utilizado pelo município de Belo Horizonte sob a nomenclatura TCG (Termo de Compromisso de Gestáo), mediante o Decreto $\mathrm{n}^{\circ}$ 12.634, de 22 de fevereiro de 2007. Cabe destacar que o modelo do Termo de Ajustamento de Gestáo (TAG) vem se disseminando nacionalmente, sendo instituído por Tribunais de Conta de estados como Minas Gerais, Goiás, Amazonas, entre outros.

10 Exposição de Motivos n 007, de 17 de maio de 1983. Para maiores informações, ver Brasil (1985).

11 Para maiores informaçóes, ver: Lee (2001) e Lobo (2003).

12 Cintra, Grinover e Dinamarco (1998) afirmam que antes do Estado deter o poder de impor a forma de direito que lhe aprouvesse e o realizasse mediante a jurisdição, houve três fases distintas: a autotutela, a arbitragem facultativa e a arbitragem obrigatória.

13 A emergência do discurso do consenso é evidenciada por Lautier (2010) quando o mesmo chama a atençáo para o processo de mudança de foco dos debates sobre políticas públicas na América Latina e no resto do mundo que teriam passado da ênfase no conflito para o consenso. Segundo o autor, dos anos de 1940 a meados dos anos de 1990 houve uma série de debates políticos e conflitos intensos em grande parte dos países. Contudo, todo esse ambiente de debate político ocorrido dos anos 1940 a meados dos anos de 1990 teria perdido clareza a partir dos anos 1990 e acabado por desaparecer por completo no início dos anos 2000, dando lugar a um consenso que se desdobra em vários campos. Para Lautier, em termos de políticas sociais, a funçáo do consenso é a de terminar e proibir o debate antes mesmo que ele se inicie, eliminando a questáo dos direitos e da democracia da discussão sobre tais políticas em nome de uma evidência moralmente fundada e de uma comunidade de valores nunca verificada.

\section{BIBLIOGRAFIA}

ACSELRAD, Henri; BEZERRA, Gustavo \& GAVIRIA, Edwin. (2010), "Inserción económica internacional y 'resolución negociada' de conflictos ambientales en América Latina”. Eure, 36 (107): 27-47.

ADORNO, Sérgio. (1996), A gestão urbana do medo e da insegurança: violência, crime e justiça penal na sociedade brasileira contemporânea. Tese de livre-docência, Universidade de São Paulo, São Paulo.

ALEMÃO, Ivan da Costa \& BARROSO, Marcia Regina. (2011), "Direito e Justiça: dificuldades na via extrajudicial". Revista Sociologia Jurídica, 12: 1-23.

BECKER, Howard. (2008), Outsiders: estudos de sociologia do desvio. Rio de Janeiro, Zahar.

BOURDIEU, Pierre. (1989), O poder simbólico. Rio de Janeiro, Bertrand Brasil.

BRASIL. (1985), Juizado especial de pequenas causas. Organização dos textos, notas remissivas e índices por Juarez de Oliveira. São Paulo, Saraiva.

CÂMARA da Reforma do Estado. (1995), Plano Diretor da Reforma do Aparelho do Estado. Brasília. Disponível em http://www.biblioteca.presidencia.gov.br/publicacoes-oficiais/catalogo/ fhc/plano-diretor-da-reforma-do-aparelho-do-estado-1995.pdf, consultado em 24/07/2018.

CAPPELLETTI, Mauro \& GARTH, Bryant. (1988), Acesso à Justiça. Porto Alegre, Fabris.

CAPPELLI, Sílvia. (2002), "Atuação extrajudicial do MP na tutela do meio ambiente". Revista do Ministério Público, 46: 230-260.

CINTRA, Antônio Carlos de Araújo \& GRINOVER, Ada Pellegrini; DINAMARCO, Cândido. (1998), Teoria Geral do Processo, São Paulo, Malheiros.

COUTINHO, Marcos Pereira Anjo. (2006), ”A invalidação do termo de ajustamento de conduta”. De Jure - Revista Juridica do Ministério Público do Estado de Minas Gerais, 7: 428-439. 
DE MIO, Geisa Paganini. (2005), O Inquérito Civil e o Termo de Ajustamento de Conduta como instrumentos efetivos para resolução de conflitos ambientais: a experiência da Promotoria de Justiça do Meio Ambiente da Comarca de Sáo Carlos - SP. Tese de doutorado, Universidade de São Paulo, São Carlos.

FAO, Food and Agriculture Organization. (1998), Integrated coastal area management and agriculture, forestry and fisheries: FAO guidelines. Rome, FAO.

FERRAZ, Luciano. (2011), “Termos de Ajustamento de Gestão (TAG): do sonho à realidade". Rere - Revista Eletrônica sobre a Reforma do Estado, 27: 81-92. Disponível em http://www. direitodoestado.com.br/artigo/luciano-ferraz/ termos-de-ajustamento-de-gestao-tag-do-sonho-a-realidade, consultado em 24/07/2018.

FOUCAULT, Michel. (1999), Em defesa da sociedade: curso no Collège de France (1975-1976). São Paulo, Martins Fontes.

FOUCAULT, Michel. (2011), A verdade e as formas jurídicas. Rio de Janeiro, Nau.

LAUTIER, Bruno. (2010), "O consenso sobre as políticas sociais na América Latina, negação da democracia?”. Caderno CRH, 23 (59): 353-368.

LEE, João Bosco. (2001), "O problema do direito aplicável ao mérito do litígio na arbitragem comercial internacional”, in D. Armelin et al. (orgs.), Arbitragem e seguro, São Paulo, Max Limonad.

LITTLE, Paul E. (2001), "Os conflitos socioambientais: um campo de estudo e de ação política”, in M. Bursztyn (org.), A difícil sustentabilidade: politica energética e conflitos ambientais, Rio de Janeiro, Garamond.

LOBO, Carlos Augusto da Silveira. (2003), "Uma introdução à arbitragem comercial internacional", in R. Almeida (coord.), Arbitragem interna e internacional: questóes de doutrina e práti$c a$, Rio de Janeiro, Renovar.

MACIEL, Marco. (1997), "Arbitragem e avanço institucional". Revista do SFI, 3. Disponível em http://www2.senado.leg.br/bdsf/bitstream/ handle/id/201155/arbitragemeavanco.pdf?sequence=1, consultado em 24/7/2018.

MAZZILLI, Hugo Nigro. (2006),“Compromisso de ajustamento de conduta: evolução e fragilidades e atuação do Ministério Público". Revista de Direito Ambiental, 11 (41): 1-19.

MOUFFE, Chantal. (1996), O regresso do político. Lisboa, Gradiva.

NADER, Laura. (1996), "A civilização e seus negociadores: a harmonia como técnica de pacificação”. Anais da XIX Reuniāo Brasileira de Antropologia. Niterói, ABA.

RANCIÈRE, Jacques. (1996), O desentendimento. São Paulo, Editora 34.

RODRIGUES, Geisa de Assis. (2000), Termo de Ajustamento de Conduta: a construção de uma solução extrajudicial de conflitos transindividuais democrática. Tese de doutorado, Universidade Estadual do Rio de Janeiro, Rio de Janeiro.

RODRIGUES, Geisa de Assis. (2002), Ação Civil Pública e Termo de Ajustamento de conduta: teoria e prática. Rio de Janeiro, Editora Forense.

SADEK, Maria Teresa. (2004), "Judiciário: mudanças e reformas". Estudos Avançados, 18 (51): 79-101.

SCHUCH, Patrice. (2008), “Tecnologias da não violência e modernização da Justiça no Brasil: poderes, saberes e éticas". Anais da 26 Reunião da Associação Brasileira de Antropologia. Porto Seguro, ABA.

SILVA, José Afonso da. (1964), Principios do processo de formação das leis no Direito Constitucional. São Paulo, Revista dos Tribunais.

SIMIÃO, Daniel Schroeter. (2007), "Madam, it’s not so easy': modelos de gênero e justiça na reconstrução timorense", in K. C. Silva e D. Simião (orgs.), Timor-Leste por trás do palco: a cooperação internacional e a dialética da formação do Estado, Belo Horizonte, Editora UFMG.

SOUSA SANTOS, Boaventura de; MARQUES, Maria Manuel \& PEDROSO, João (1996), "Os tribunais nas sociedades contemporâneas". Revista Brasileira de Ciências Sociais, 11 (30): 29-62.

VIDAL, Cláudia Márcia Gonçalves. (2008), "Juizado Especial Criminal. Passo a passo. Um diálogo com o povo". Banco do Conhecimento, Portal do Tribunal de Justiça do Rio de Janeiro. Disponível em http://www.tjrj.jus.br/c/document_library/get_file?uuid=1b840208-ba31-406e-9a8a-6b753af96ba5\&groupId=10136, consultado em 24/7/2018. 


\section{A CONSTRUÇÃO LEGAL- INSTITUCIONAL DA \\ RESOLUÇÃO NEGOCIADA DE CONFLITO NO BRASIL}

\section{Rodrigo NuñezViégas}

Palavras-chave: Reforma do Estado; Reforma do sistema de Justiça; Conflito social; Pacificação; Métodos e instrumentos extrajudiciais.

No presente artigo pretendemos identificar as iniciativas realizadas na esfera legislativa para a consecução da reforma do sistema de Justiça, desenvolvida no Brasil a partir dos anos 1980. Buscamos demonstrar que tais iniciativas envolvem um processo - ao contrário de uma tendência ocorrida mundialmente de enxugamento das legislaçóes - de expansão da legislação brasileira como forma de regulamentar órgáos, métodos e instrumentos extrajudiciais de tratamento dos conflitos. Ademais, procuramos evidenciar tal processo como resultado do esforço de certos "criadores de regras" que, ao criarem e imporem regras, buscam reconfigurar o que se entende por função "pacificadora" do Estado de tratar os conflitos, justificando suas açóes por meio de discursos que reforçam a via extrajudicial como maneira de tornar mais "pacífico", "consensual" e "célere" o tratamento dos conflitos.

\section{THE LEGAL-INTITUTIONAL CONSTRUCTION OF NEGOTIATED RESOLUTION OF CONFLICT IN BRAZIL}

Rodrigo NuñezViégas

Keywords: State Reform; Justice System Reform; Social conflict; pacification; extrajudicial methods and instruments.

In this article, we aim to identify the initiatives carried out in the legislative to achieve the reform of the justice system, developed in Brazil starting in the 1980s. We intend to demonstrate that these initiatives involve a process of legislation expansion - contrary to a worldwide tendency of downsizing it - as a means of regulating extrajudicial organs, methods and instruments for dealing with conflict. Furthermore, we aim to emphasize such process as the result of the struggle of certain "rule makers" which, in creating and imposing rules, seek to reconfigure the understanding of the "pacifying" function of the state when dealing with conflicts, justifying their actions through speeches that reinforce the extrajudicial means as the way to make the conflict resolution "quicker", more "peaceful" and "consensual".

\section{LA CONSTRUCTION LÉGALE ET INSTITUTIONNELLE DE LA RÉSOLUTION NÉGOCIÉE DE CONFLITS AU BRÉSIL}

\author{
Rodrigo NuñezViégas
}

Mots-clés: Réforme de l'État; Réforme du système judiciaire; Conflit social; $\mathrm{Pa}$ cification; Méthodes et instruments extrajudiciaires.

Nous nous proposons, dans cet article, d'identifier les initiatives entreprises, à partir des années 1980, dans le domaine législatif, pour la réforme du système judiciaire au Brésil. Nous avons tenté de démontrer que de telles initiatives impliquent en un processus qui, contrairement à une tendance mondiale de simplification des législations, visent à accroitre la législation brésilienne en vue de réglementer les organes, les méthodes et les instruments extrajudiciaires de traitement des conflits. Nous tentons également dedémontrer que ce processus fait suite à un effort de certains " créateurs de règles " qui, tout en créant et en imposant de nouvelles règles, cherchent,pour faire face aux conflits, à reconfigurer ce qui est compris comme étant la fonction «pacificatrice» de l'État. Ils justifient leurs actions par des discours qui renforcent la voie extrajudiciaire, qui devient la manière derendre le traitement des conflitsplus "pacifique», "consensuel» et «rapide». 